\title{
Questioning Seeding Rates and its Influence on Phenotypic Expression of Wheat Populations for Participatory Plant Breeding-First Findings from Field Research across Organic Farms in Belgium and the Netherlands
}

Sofia Baltazar ${ }^{1, *, \dagger}$, Raphaël Boutsen ${ }^{2, \dagger}$, Lieven Delanote ${ }^{3}$, Vincent Delobel ${ }^{4}$, Karel Dewaele ${ }^{3}$ Willem Stoop $^{5}$ and Marjolein Visser ${ }^{2}$

${ }^{1}$ University of Namur, Namur, Belgium

2 Université Libre de Bruxelles, Brussels, Belgium

${ }^{3}$ Inagro VZW, Rumbeke-Beitem, Belgium

${ }^{4}$ Chèvrerie de la Croix de la Grise, Havinnes, Belgium

${ }^{5}$ Consult: R\&D for Tropical Agriculture, Driebergen-Rijsenburg, The Netherlands

$\dagger$ Both authors have contributed equally to the research presented in this paper.

* Corresponding author: E-Mail: sofia.baltazar@unamur.be; Tel.: +32 81724472

Submitted: 20 July 2018 | In revised form: 28 November 2018 | Accepted: 17 May 2019 |

Published: 2 October 2019

\begin{abstract}
In Belgium and The Netherlands, bread wheat (Triticum aestivum L.) is getting attention within a growing movement looking for more sustainability of wheat cropping and breadmaking. The few varieties available are pure lines that do not match the wide range of environments and organic farming practices, so that yields and milling quality are often disappointing. Composite Cross Populations (CCP) have been created with the idea of evolutionary plant breeding through on-farm mass selection and seed saving. In 2015-2016, one such CCP of winter wheat was cropped side by side with a pure line variety in four organic farms with different wheat cropping practices, as a first step to answer some of the concerns arising from farmers' networks we work with. Seeding rates ranged from the standard high to the very low ones practiced under the System of Wheat Intensification (SWI). Multivariate data analysis confirmed greater differentiation of the CCP both compared with pure line varieties and within populations on farms where inter-plant competition was less intense. Low seeding rates thus seem to enhance the phenotypic expression potential of a CCP, yet this is a neglected fact among participatory plant breeders. Since both CCP and SWI have great potential for ecological intensification within organic farming, we argue that more work is needed on finding new ways of combining innovation in farming practices and on-farm plant breeding, which also implies new ways of organising research.
\end{abstract}

Keywords: Composite cross populations; organic farming; participatory plant breeding; evolutionary plant breeding; seeding rate; system of wheat intensification 


\section{Introduction}

Bread has always been and remains an emblematic staple food. Yet bread wheat (Triticum aestivum L.) cropping has declined in temperate Europe, to the point where most farmers grow low-quality wheat for animal feed and most bread grain is imported for an increasingly large-scale and globalised bread baking industry [1]. However, there is a growing interest in bread wheat for the purpose of local milling, small-scale bread baking and marketing. This interest is leading to a widening network connecting farmers, bakers, millers, households, as well as researchers [2]. Within this bread wheat renewal and accompanying research, two distinct innovations in wheat cropping come to the fore:

- Evolutionary and participatory plant breeding with population varieties, addressing the seed question in farming;

- The System of Wheat Intensification (SWI), addressing the need for ecological (re)intensification within low external input systems.

\subsection{The Seed Question in Farming}

Post-war plant breeding served an industrialised and largescale agriculture relying on high levels of farm-external inputs. It thus created genetically uniform varieties with pure-line or $\mathrm{F} 1$ hybrid breeding, complying with legislative criteria of homologation: distinction, uniformity and stability (DUS-criteria). One of the consequences of this evolution was the continuous decline of cultivated biodiversity, both inter- and intra-specific. An example of this decline is the genetic erosion of bread wheat in France between 1912 and 2006, even though the number of commercial varieties has grown [3]. Although modern wheat breeding enabled substantial yield gains, intensive focus on this criterion led to downside effects such as poor energy and nutrient efficiency, lower mycorrhizal responsiveness [4] or decrease of mineral contents and thus nutritional value [5]. Furthermore, crop genetic diversity can benefit farmland diversity, such as soil arthropods in cultivated fields [6] and enhance current and future ecosystem services such as pest and disease control, carbon sequestration, prevention of soil erosion, pollination etc. [7]. A strategic ecological aspect of low external input farming is its adaptation to greater environmental diversity and variability than high external input farming. Moreover, and because of multiple Genotype $x$ Environment interactions, it needs genetically diverse varieties which have a capacity to evolve spontaneously, as a population, in response to selection pressures that vary in space and time. In this respect, evolutionary plant breeding (population breeding within the target environment) seems promising as well as inexpensive. Interestingly, it had already been described in the 1920's before sinking into oblivion [8,9]. One particularly interesting outcome of the revival of evolutionary plant breeding is a collection of Composite Cross Populations (CCP) of wheat and oats. CCPs of wheat were created through the crossing of many modern bread wheat cultivars of the European Catalogue in all directions and subsequent seed increase without actively selecting particular genotypes throughout the segregating generations [10].

\subsection{Decentralized and Participatory Plant Breeding}

Evolutionary plant breeding is a particularly interesting option in the context of decentralized and participatory plant breeding. According to Wolfe et al [11], decentralized breeding is needed in order to take into account genetic diversity in breeding strategies. This in-situ breeding is conducted directly within diverse target environments and includes cropping practices such as the ones described next. First it seeks to favour local adaptation by enhancing Genotype $x$ Environment interactions. Secondly, participatory plant breeding (PPB) takes it still one step further and can be defined as the participation of several actors (farmers, consumers, researchers...) in the breeding process. PPB is based on complementing knowledge and know-how of each participant [12-14]. Numerous approaches to PPB exist, from passive participation to self-mobilization $[15,16]$. Even though in its early days it was confined to southern countries, PPB is now emerging as a practice with accompanying research in Europe [15,17-23]. As a result of these initiatives, genetically diverse wheat seed is increasingly available for trials. This is our first starting point.

\subsection{The System of Wheat Intensification (SWI)}

Our second starting point tackles the diversity of farmers, their fields and practices of wheat growing. Apart from the diversity in field conditions, also crop management practices such as seeding rates and a series of interconnected practices, like seeding date, insertion within rotations, intercropping, weed management, seed saving and selection, might considerably affect the crop environment thus also Genotype x Environment interactions, the focus of attention of decentralized breeding. The System of Wheat Intensification (SWI) is called after the System of Rice Intensification (SRI), which was developed in Madagascar and described in 2002 [24]. The common basis is a drastically reduced plant density in the field. Since then, farmers and researchers have begun adapting and extrapolating its principles to a range of other crops, so that we can now speak of a general System of Crop Intensification (SCI) $[25,26]$. The SCl has been reassessed by emphasizing aspects of basic crop husbandry and soil life, challenging a series of blind spots of mainstream agronomy and plant breeding that underpinned the Green Revolution [27,28]. In a nutshell, the SWI consists of a set of interrelated practices: a considerably reduced seeding rate to lower intra-crop competition (from the conventional $150-200 \mathrm{~kg} / \mathrm{ha}$ to rates as low as 20-40 kg/ha), early seeding (for winter wheat ideally before October in temperate Europe), precision seeding allowing for precise spacing and mechanical weeding. Seeds are 
saved by selecting the most vigorous grains on the basis of 1000 grain weight (ideally toward $60 \mathrm{~g}$ per 1000 seeds). Admittedly, these are labour-intensive practices; yet they work synergistically by stimulating profuse tillering, maximal ear development and minimal tiller death. In all, individual plant vigour, health and total grain yield are improved with minimal costs or external inputs. Interestingly also, the low densities enhance the phenotypic expression of the genotype, which has significant consequences for plant breeding. Some plant breeders now challenge the standard practice of high seeding density in wheat that became entrenched during the twentieth century $[29,30]$ as there is a trade-off between two ways of obtaining a satisfying yield: either by selecting on the potential to make the most of available resources (through tillering) or by selecting on competitive ability in crowded and resource-limiting conditions (a strategy promoted by seed companies).

The question is then obviously: do CCPs express themselves better under SWI compared to standard practices favouring high seeding rates? If yes, it would mean that the introduction of CCPs for the purposes of on-farm population breeding should go hand in hand with radical changes in the way these are cropped, i.e. through systems allowing a better phenotypic expression of their genetic potential and diversity, thus easing in-situ and mass selection. However, such change in wheat cropping practice may require change in connected practices (e.g. timing of various operations like land preparation, weeding and the use of fertilisers, etc.). Hence, relevant on-farm experimentation is needed to explore the combination of these ideas and answer questions raised by organic farmers. Nevertheless, this involves various implementation and analytical constraints, as described in the next sections. Thus new experimental approaches are needed for embracing rather than excluding the serendipity inherent to on-farm realities.

As part of a larger participatory research with bread cereals networks, the present paper specifically asks three interrelated questions: (i) How does one particular CCP behave (for all recorded parameters) compared to a pure-line variety under four different cropping systems?. (ii) Does radically reducing seeding rates (the basis of SWI) enhance the phenotypic expression and thus the potential for onfarm mass selection and seed saving within a CCP?. (iii) How can experimental tools and approaches become more useful and relevant for organic on-farm research?

\section{Material and Methods}

\subsection{Overview}

In order to answer the questions above, in 2015-2016 four field trials were established in four organic farms located in the West of Belgium and in the Netherlands (Zeeuws Vlaanderen, South of the Scheldt Estuary). We systemat- ically compared one and the same CCP with a pure line variety within these four different cropping systems that use variable seeding rates (Table 1). Within each farm environment, we observed the differences in phenotypic variation between the CCP and the pure line variety (cropped side by side) for a number of phenotypic traits. We considered this variation an estimate of the inherent phenotypic expression of the genetic variation contained in the CCP.

\subsection{Plant Material}

Two types of wheat cultivars were tested: (i) a genetically heterogeneous modern population and (ii) modern pure lines.

The Composite Cross Populations used in this experiment originated in the John Innes Centre (Norwich, UK), through the half-diallel crossing of twenty European wheat varieties in 2001 . The aim was to create three separate populations in order to reintroduce diversity in wheat cropping. Parent varieties chosen for the CCP were selected for either good baking quality or high yield, among varieties that were well known and had performed well over the last few decades in the UK. The first population is made up of 66 crosses between varieties with good milling potential (Q), the second of 36 crosses between varieties identified as having high yield potential $(Y)$ and the third one of the 99 crosses between $Y$ and $Q$ parents (YQ). The procedure has been described in detail by several authors [31-34]. After being grown for three generations in three sites in the UK, grains from these different sites were bulked up and the three populations were sent to the University of Kassel (Germany). In the 2005-2006 season, each population was split in two and grown both organic $(\mathrm{O})$ and conventionally (C). In 2006-2007, two parallel populations were created for each population (I and II), meaning that there were in total twelve distinct CCPs. In 2013, the Flemish research centre of INAGRO (organic farm) received the F13 of six organic populations. The population used in this study is the F14 of OYQI that was harvested in 2015 in INAGRO.

The pure line varieties were Julius, Edgar and Ubicus. These bread wheat varieties with high yield potential are commonly used in organic farms in Belgium and the Netherlands. They all have relatively short straw (on average $90 \mathrm{~cm}$ ).

\subsection{Field Trial Site and Experimental Design}

Four field trials were established in four organic farms located in the West of Belgium and in the Netherlands: VD (N 50.6299 and $E$ 3.4877) and PC (N 50.5808 and E 3.5415) in Wallonia, the organic experimental farm of the research centre of INAGRO (IN; N 50.9017 and E 3.1244) in Flanders, and the Dutch site (CS) in Noord Beveland (N 51.5527 and $E$ 3.7186). Table 1 details some aspects of cropping practices of these farms. 


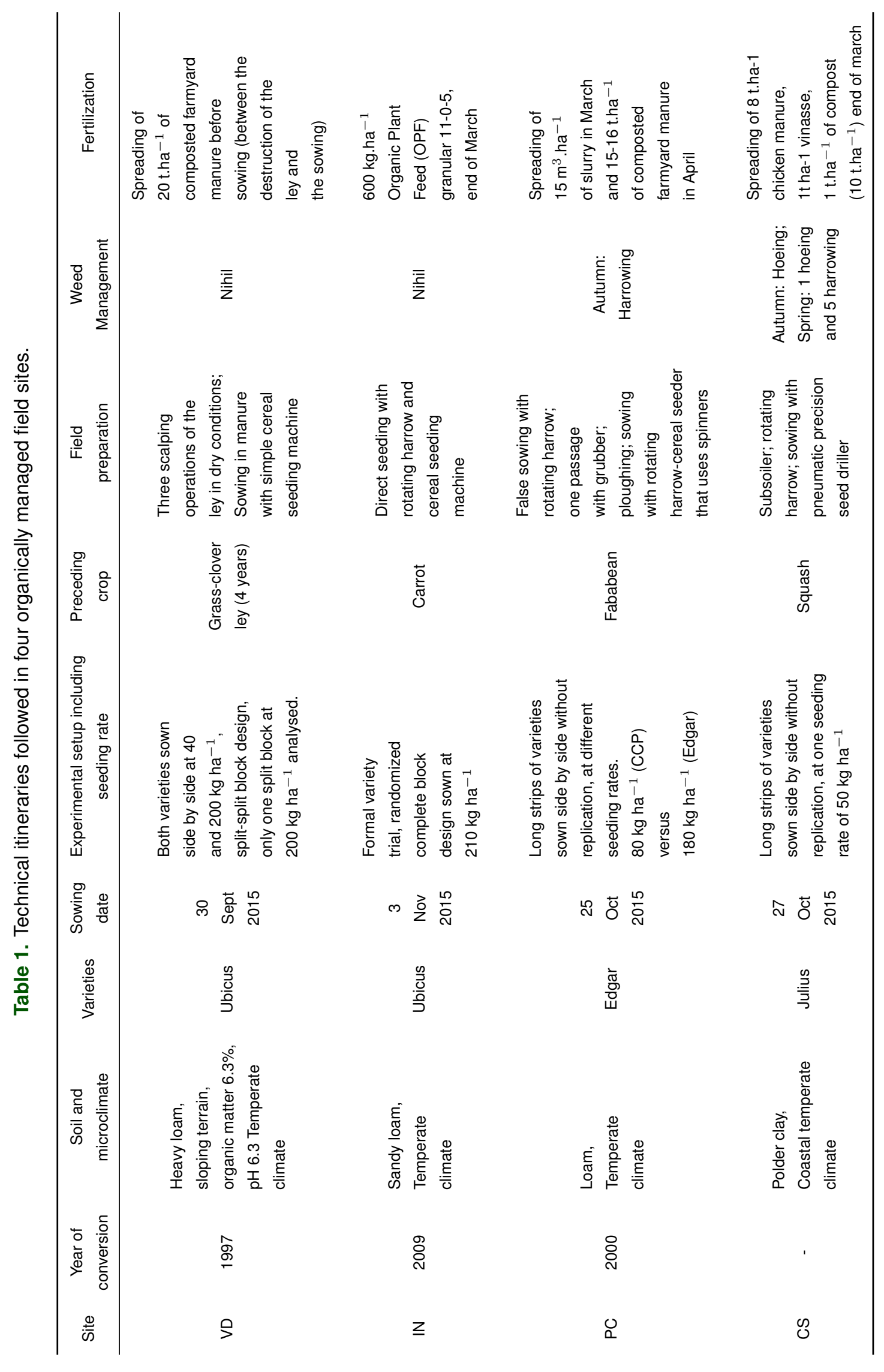


All field trials were established in autumn 2015 and followed up throughout the winter growing season. All observations were carried out in July 2016, just before harvest. Although each trial contains the same CCP, the identity of the pure line variety differed as well as how it was compared with the CCP, due to management differences associated with the four different farms (see Table 1). Such differences between farms constitute a common problem in on-farm research. Hence, the desired standardisation of experimental designs may not always be possible, complicating the statistical analyses of the collected data, as the paper will illustrate. At the same time, however, the approach may provide unexpected sources of practical information.

In VD, a split-split block design was conducted with two factorial contrasts: CCP versus pure line variety on the one hand and high versus low density seeding on the other. Each split-split block was repeated four times. However, only one split-split block (contrast Ubicus-CCP under high density seeding) was usable for data collection. Elsewhere in the field, the wheat plants were either lost to bird attacks (because of the early sowing date) or overgrown by perennial grasses of the previous ley that was not sufficiently destroyed prior to seeding. Across that remaining split block, we established four successive blocks a posteriori, where the CCP could be compared with Ubicus side by side. This site was clearly marked by a low survival rate and an intense competition from weeds so that the initial seeding rates had lost their meaning.

At the experimental organic farm of INAGRO (IN), a variety trial was composed by 7 pure-line varieties (among which Ubicus) and 8 different CCPs (among which OYQI) and organized in four randomized complete blocks. In the present study, in order to be able to compare the data with the other sites, we focused within this trial on Ubicus for the pure-line variety and CCP (OYQI) for the composite cross population. All varieties in all blocks were sown at the same density. We used the four existing blocks to replicate the comparison of Ubicus with the CCP. The Inagro site was clearly marked by an intense intra-crop competition due to the high seeding rates (which resulted in high plant densities) and to some extra competition by weeds (mainly Poa annua L. and Stellaria media L.).

In the last two sites (PC and CS), the same CCP was sown in long narrow strips (corresponding to half or full seeder length) side by side with a pure line variety (Edgar and Julius respectively). This simplified setup only allowed for establishing four successive blocks a posteriori across both strips (variable width; 20m length), similar to VD. CS is regarded as the environment where intra-crop competition was lowest due to the application of SWI, whereas PC was intermediary to IN and CS.

\subsection{Data Collection}

For each block in each site, 10 plants per variety were selected and marked to encompass the phenotypic differentiation of the crop as revealed through easily observable phenotypic traits (40 plants per variety and per site, 320 plants in total). We recorded ear density (number of ears $\mathrm{m}^{-2}$; ED) around the marked plant (at the centre of a circle with a radius of $34.5 \mathrm{~cm}$ ). The 320 marked plants were then dug out to record individual plant traits in the laboratory.

\subsection{Phenotypic Traits and Yield Components}

Phenotypic traits and yield components were measured on each plant. The choice of parameters was inspired from Rivière et al. [19], adding straw width and tillering while leaving out counts of the number of fertile and sterile spikelets per ear. Phenotypic traits included: total number of tillers (TNT), number of fertile tillers (NFT) and length of the longest tiller (ear included; $\mathrm{H}$ ). On this longest tiller (considered to have exerted apical dominance over the others) ear length (cm; LE), distance between the ligule of the flag leaf and the base of ear (cm; DBFLE) and straw width $(\mathrm{mm}$; measured with sliding callipers; SW) were assessed. The following yield components were measured: number of grains per ear (NGE), total dry grain weight per ear ( $g$; GWE), thousand grain weight (ratio of GWE over NGE $x$ 1000; g; TGW), besides ear density (ED; measured in the field and the only per area basis parameter).

\subsection{Statistical Analysis}

Data were analysed by combining a univariate with a multivariate approach.

We used a univariate approach to assess first, for which traits and in which sites the differentiation of the CCP from a pure line variety was clearest overall (notwithstanding variation within the CCP for these traits). However, it was not possible to carry out a unique ANOVA with two factors (crossing site and variety) because the experimental designs and pure lines varieties were not the same in each site. For each site however, we compared the CCP with the pure line variety with a one-factorial ANOVA accounting for blocks.

Second, to compare the intra-varietal variation between the CCP and the pure line variety among the four sites, we applied a paired-samples Student's t-test with a one-sided significance test (variability supposed to be greater within the CCP) on the means of standard deviations of each parameter (one standard deviation per block and per variety, corresponding to a series of four pairs of values of standard deviation per variable).

As regards the multivariate approach, a Principal Components Analysis (PCA) was carried out. Indeed, the way the CCPs were sown in different farms by different teams acting independently from one another was not conform to standard agronomical trials. PCA is not based on a priori assumptions but rather seeks to establish ecological patterning, in this case within and among varieties and sites. PCA was carried out on all 320 ( 4 sites $\times 4$ blocks $\times 2$ varieties $\times 10$ plants) individuals on all phenotypic parameters and yield components (10 variables). The resulting biplots 
of 320 points and ten vectors (projected on the first three principal components) were then overlaid with the identifier variables of site and variety to detect overall patterns.

Data were analysed with R Studio (ANOVA and PCA) using the packages "vegan", "cluster" and "agricolae" [35-37] and with Excel (paired samples t-test on standard deviations). We used Box plots instead of error bars in the univariate figures for better transparency on the recorded variation of each trait (outliers being hidden by error bar technique).

\section{Results}

We first describe the inter-varietal differences as revealed through the ANOVA per site and per variable, then analyse the intra-varietal variation as revealed through the t-tests per site and per variable (Table 2). Finally, the PCA correlates all variables with regard to site and varietal differences among the 320 individual plants (Figures 3 and 4 and Table 3).

\subsection{Differences Between Varieties}

\subsubsection{Vegetative parameters}

The parameters that varied most markedly were total number of tillers and number of fertile tillers per plant. Averaged per site and per variety, these range from 1.5 tillers with 1.0 fertile tiller (IN) to 14.6 tillers with 14.1 fertile tillers (CS; Table 2). However, to meaningfully compare varietal differences within one site, site-specific uncontrolled variation needs to be brought in. In PC, the seeding rate of the CCP is half the seeding rate of the pure line variety. Here, the more intense tillering of the CCP confounds variety effects with seeding rates. In CS, the pure-line plots were invaded by slugs in the spring, which created gaps in the canopy. Here, the more intense tillering of the pure line is the direct result of gap creation (also reflected in the significantly lower ear density of the pure line). In IN, the dense homogeneous seeding without accidents during the tillering phase resulted in a quasi-absence of tillering and the typical Donald [38] ideotype (one seed yields ideally one and maximum two fertile tillers) for both varieties. However, under the conditions of extreme competition from perennial grasses in the VD site, the surviving CCP plants tillered significantly more (4 versus less than 3 tillers) and yielded significantly more fertile tillers than the surviving pure line plants (3 versus 2 tillers; Table 2).

For all sites, the CCP grew significantly higher (respec- tively $94.4,102.6,116.1$ and $118.1 \mathrm{~cm}$ ) compared to the pure lines (respectively 88.3, 92.3, 89.5 and $83.9 \mathrm{~cm}$; Table 2). Yet very little to no lodging was observed in the CCP plots, despite the exceptionally adverse growing conditions of 2015-2016 experienced all over temperate Europe (Anonymous, 2016). Regarding straw width, this parameter varied slightly between sites, but the CCP systematically had a significantly larger width of straw compared to the pure lines (Table 2). CCP straw was thus systematically higher and thicker than pure line straw.

On one hand the distance between the flag leaf and the ear basis (DBFLE) of the CCP plants was significantly higher in those sites where the differences in straw height with the pure line variety were the most important (PC and $\mathrm{CS}$ ). As this distance is a measure of the elongation of the last vegetative internode, it is an indicator of the degree of expression of the growth potential of the individual plant. On the other hand, no differences in DBFLE could be observed in VD and IN, where the CCP straw height differed less (but still significantly) with the pure line varieties.

\subsubsection{Generative growth}

On average, ear length (LE) of the CCP was significantly higher than of pure lines in three sites (VD, IN and CS) with respectively $9.7,8.7$ and $11.6 \mathrm{~cm}$ for the CCP and 8.4, 7.8 and $9.4 \mathrm{~cm}$ for pure lines. However, the mean number of grains per ear (NGE) or the total grain weight (GWE) per ear did not differ significantly between varieties in any of the sites (Table 2). Taken together, this means that the longer ears of the CCP were composed of less densely packed spikelets.

\subsubsection{Yield components}

While the mean number of grains and total grain weight per ear did not differ significantly between varieties (Table 2), the mean number of grains per ear varied greatly between sites, from 32 (IN) to 60 (CS) on average. Interestingly, thousand grain weight varied greatly between sites yet showed inter-varietal differences in two sites only (PC and CS). In these sites, the CCP had on average a higher thousand grain weight than the pure line (respectively in PC 40.3 vs. $34.3 \mathrm{~g}$, in CS 42.5 vs. $37.7 \mathrm{~g}$ ). In the other two sites (VD and IN) differences were not significant between varieties (Table 2), but IN recorded extremely high individual values of thousand grain weight compared to the other sites (Figure 1). 
Table 2. Phenotypic trait means and standard deviations (SD) per farm and per wheat variety of ten plant parameters (see Table 3 for their description). Farms are arranged from the strongest to the weakest inter-plant competition environment. Means and SD are highlighted when significantly $(p<0.05)$ higher than corresponding variety means and SD within the same site. Per farm, varietal means were compared through one-factorial ANOVA accounting for blocks and SD were compared through a paired-samples t-test.

\begin{tabular}{|c|c|c|c|c|c|c|c|c|c|c|c|c|}
\hline & & & NFT & TNT & $\begin{array}{c}\mathrm{H} \\
(\mathrm{cm})\end{array}$ & $\begin{array}{l}\mathrm{LE} \\
(\mathrm{cm})\end{array}$ & $\begin{array}{l}\text { DBFLE } \\
(\mathrm{cm})\end{array}$ & $\begin{array}{l}\text { SW } \\
(\mathrm{mm})\end{array}$ & NGE & $\begin{array}{l}\text { GWE } \\
(\mathrm{g})\end{array}$ & $\begin{array}{c}\text { TGW } \\
\text { (g) }\end{array}$ & $\begin{array}{c}E D \\
\left(\text { ears } m^{-2}\right)\end{array}$ \\
\hline \multirow[t]{4}{*}{ VD } & $\mathrm{CCP} 1$ & mean & 3.1 & 4.1 & 94.4 & 9.7 & 12.5 & 4.50 & 40.6 & 2.1 & 40.0 & 72.5 \\
\hline & & SD & 1.8 & 2.3 & 13.5 & 2.2 & 6.4 & 0.82 & 15.7 & 0.7 & 6.7 & 55.7 \\
\hline & pure line & mean & 2.2 & 2.7 & 88.3 & 8.4 & 13.2 & 4.08 & 34.9 & 1.9 & 40.9 & 77.1 \\
\hline & & SD & 1.8 & 2.2 & 10.3 & 1.4 & 4.4 & 0.66 & 13.1 & 0.5 & 10.8 & 54.0 \\
\hline \multirow[t]{4}{*}{ IN } & $\mathrm{CCP}$ & mean & 1.1 & 1.5 & 102.6 & 8.7 & 14.6 & 4.25 & 34.4 & 2.4 & 58.2 & 342.0 \\
\hline & & SD & 0.3 & 0.8 & 17.3 & 1.7 & 6.1 & 0.71 & 15.9 & 0.9 & 21.7 & 52.7 \\
\hline & pure line & mean & 1.0 & 1.5 & 92.3 & 7.8 & 14.7 & 3.78 & 32.2 & 2.1 & 52.1 & 400.7 \\
\hline & & SD & 0.2 & 0.8 & 8.4 & 1.1 & 2.8 & 0.48 & 13.3 & 0.7 & 10.2 & 45.9 \\
\hline \multirow[t]{4}{*}{$\mathrm{PC}$} & $\mathrm{CCP}$ & mean & 3.3 & 3.6 & 116.1 & 9.8 & 12.3 & 4.88 & 43.6 & 2.3 & 40.4 & 330.8 \\
\hline & & SD & 2.5 & 2.5 & 16.3 & 1.7 & 6.9 & 0.69 & 9.9 & 0.5 & 6.8 & 52.0 \\
\hline & pure line & mean & 1.2 & 1.3 & 89.5 & 10.2 & 10.1 & 4.33 & 45.5 & 2.1 & 34.3 & 338.0 \\
\hline & & SD & 0.6 & 0.7 & 8.4 & 1.8 & 2.1 & 0.76 & 18.9 & 0.7 & 4.1 & 44.3 \\
\hline \multirow[t]{4}{*}{ CS } & $\mathrm{CCP}$ & mean & 7.7 & 8.1 & 118.1 & 11.6 & 16.1 & 5.18 & 54.9 & 3.1 & 42.5 & 351.2 \\
\hline & & SD & 5.0 & 5.1 & 17.4 & 1.7 & 7.0 & 0.93 & 12.0 & 1.1 & 8.1 & 82.3 \\
\hline & pure line & mean & 14.1 & 14.5 & 83.9 & 9.4 & 12.9 & 4.43 & 59.5 & 2.8 & 37.7 & 309.7 \\
\hline & & SD & 7.5 & 7.7 & 13.6 & 0.8 & 2.3 & 0.71 & 9.3 & 0.3 & 3.5 & 50.3 \\
\hline
\end{tabular}

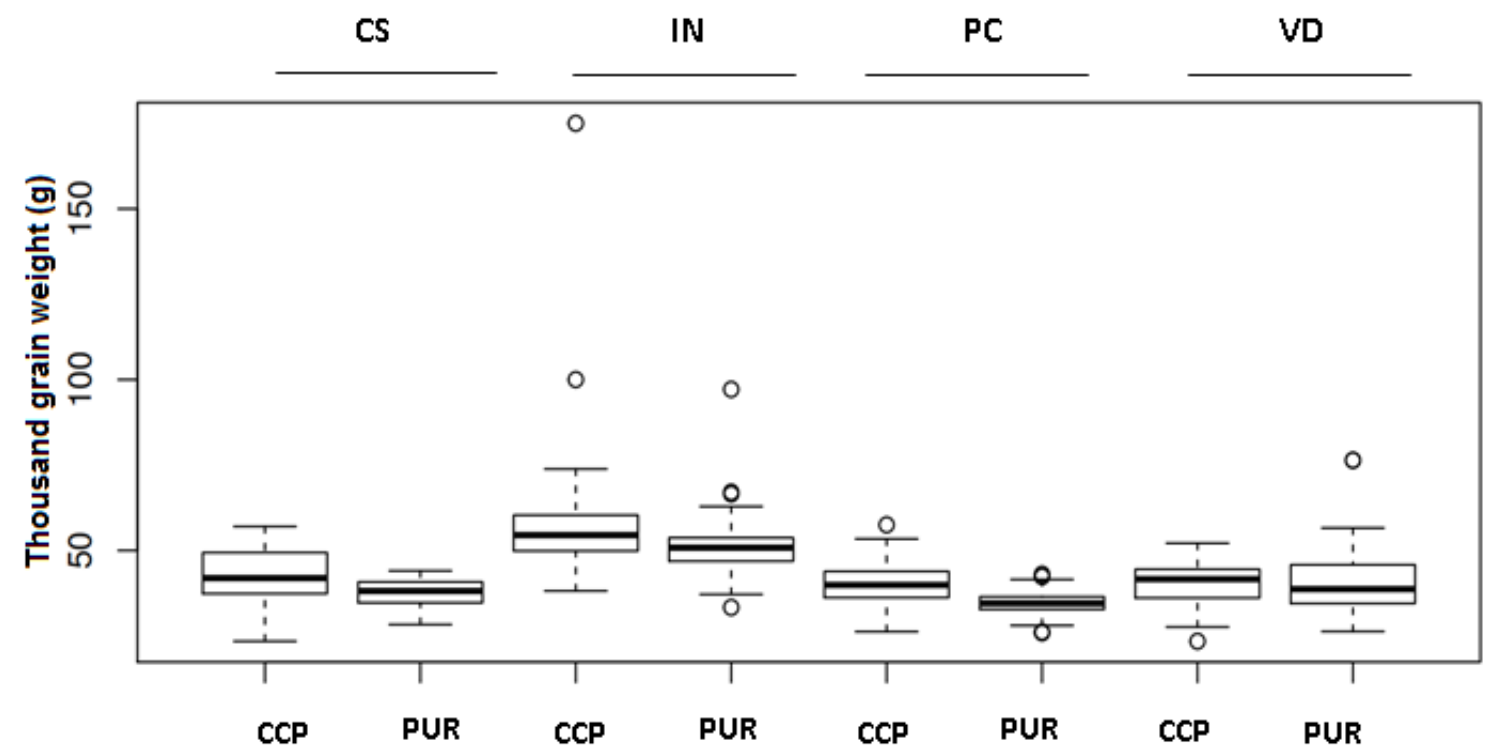

Figure 1. Box-plots of thousand grain weight for each site (CS, IN, PC and VD) and variety (CCP = Composite Cross Population, PUR = Pure line). 


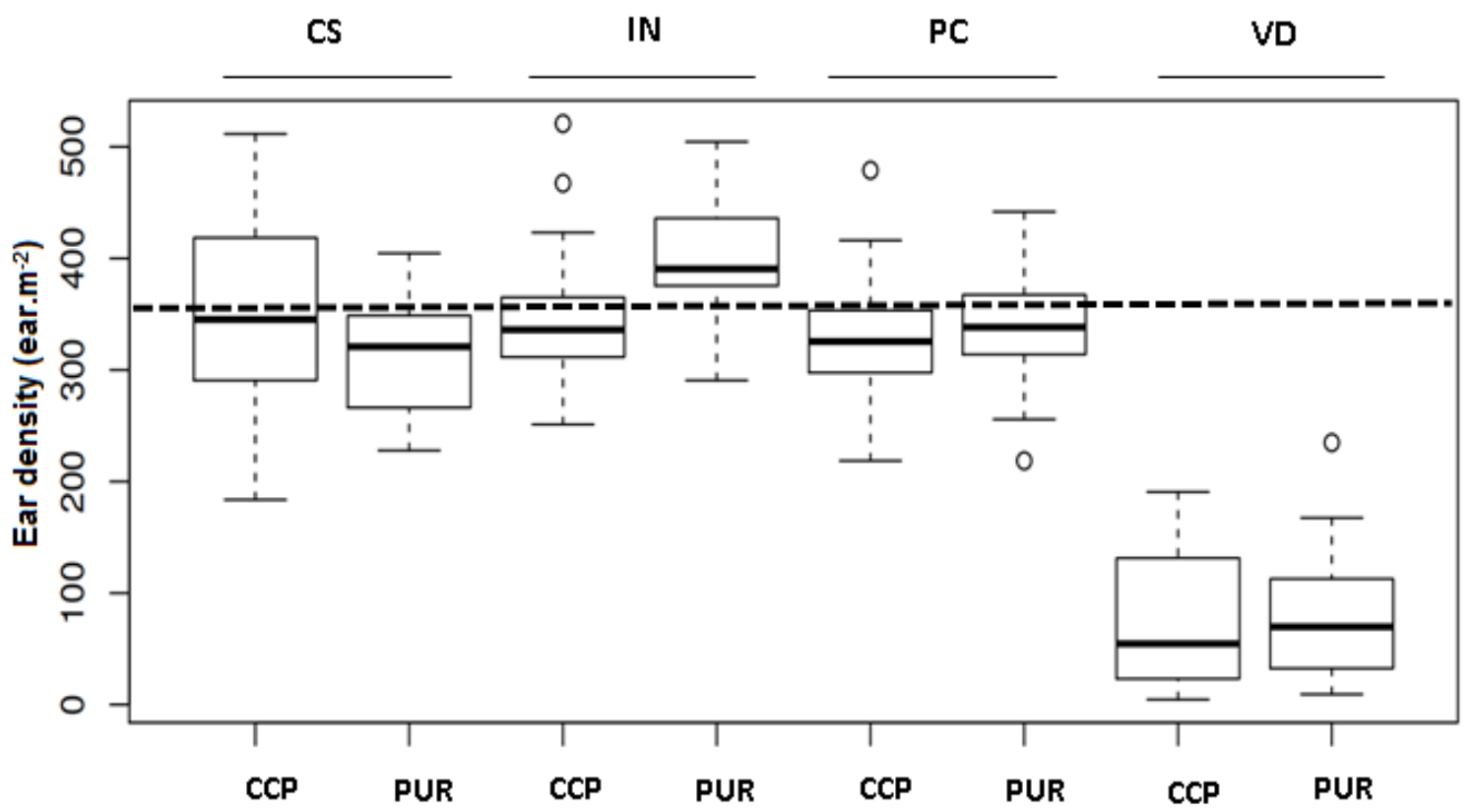

Figure 2. Box Plots of ear density $\left(\right.$ ear. $\mathrm{m}^{-2}$ ) for each site (CS, IN, PC and VD) and variety (CCP = Composite Cross Population, PUR = Pure line). The dotted line represents the mean ear density expected for pure lines grown under organic wheat cropping conditions (CREAB 2012).

Overall, Figure 2 shows a remarkable stability of ear density whatever the initial seeding rate. The exception is the site VD where the initial seeding rate contrasts were heavily compromised, resulting in very low and variable final wheat plant and ear densities. Despite this overall stability, two context-specific statistically significant differences were observed. Ear density (ears. $\mathrm{m}^{-2}$ ) differed significantly in the sites IN and CS (Table 2 and Figure 2). Under the high seeding rate (IN) the pure line ear density was higher than the CCP ear density. Conversely, in the site with a SWI approach (very low seeding rate, CS) CCP ear density was higher than pure line ear density, but note again this lower density might be due to the slug invasion of the pure-line plot. For PC the comparison is peculiar because of the big difference in seeding rates applied side by side (CCP $80 \mathrm{~kg} / \mathrm{ha}$ and pure-line $180 \mathrm{~kg} / \mathrm{ha}$ ). Despite this contrast, the final ear density was equal for both varieties (CCP: 331 ears. $\mathrm{m}^{-2}$ and pure line: 338 ears. $\mathrm{m}^{-2}$ ). This final equality despite great initial differences in seeding rate illustrates a universal tillering potential to compensate for low plant density, but not a difference in tillering potential between a CCP and a pure line. VD is the only site suggesting this difference.

\subsubsection{Variation within varieties}

In the field, we observed a large intra-varietal variation, between individual plants of the CCP around the calculated means of several parameters (height, distance between the ligule of flag leaf and the base of ear, length of ear, ears awned or not, tillering). We verified if this variability differed between sites, and in particular whether it was better expressed at lower seeding rates. For the univariate approach, we used a paired t-test, which is based on pairwise differences between the standard deviations of the CCP (due to environmental and genetic variation) and the pure line variety (due to environmental variation only), calculated per block (four replicates per site). Table 2 summarizes results. Sites are presented from high (VD) to low (CS) inter-plant competition, and along this gradient, the number of significant differences increases from one (VD) to eight (CS). In the first site (VD), only one parameter (LE) out of ten showed a significant difference of this variability: CCP had more variable ear lengths than the pure line. In the second site (IN, $210 \mathrm{~kg} / \mathrm{ha})$, four parameters (H, DBFLE, WS and LE) out of ten showed a higher variation for the CCP. In the third site (PC, CCP: $80 \mathrm{~kg} / \mathrm{ha}$ and pure line: 180 $\mathrm{kg} / \mathrm{ha}$ ), four parameters (NFT, TNT, H and LE) out of ten showed a significantly higher variation within the CCP. Two parameters (GNE and ED) were not statistically different but had a $p$ value near the threshold of significance (0.05). In the last site CS, seven parameters (NFT, TNT, H, LE, DBFLE, GWE, TGW and ED) out of ten showed significant differences in variability, and most of them were more variable for the CCP than for the pure line. However, for two parameters (TNT and NFT) the pure line showed a higher variability than the CCP. The reason might again be the slug invasion, which was not homogeneous throughout the pure line plot. Among the four farms however, the tillering of the CCP plants varied most strongly in CS. In summary, 
for most recorded variables we observed a trend confirming our hypothesis: intra-varietal variation was higher for the CCP compared to the pure line varieties, and phenotypic expression is enhanced at lower seed rates and/or with less inter-plant competition.

\subsubsection{Overall pattern within and among varieties and sites}

The first three principal components (PC1, PC2 and PC3) resulting from PCA explain $71.7 \%$ of the total variation of our dataset (respectively 38.5, 19.9 and 13.3\%). Figure 3 is the score plot of the 320 individual recordings projected on the (PC1, PC2) - plane. Three trends are obvious:

1. The colour overlay with the site variable (one colour per site) clearly separates the dots in four successive clouds along a gradient roughly indicated by the vector showing the variation in NFT.

2. The level of dispersion of the dots within each of these clouds increases along the same gradient, showing increased phenotypic variability as NFT increases.

3. The overlay with the identifier variable indicating CCP or pure line shows that as the level of dispersion increases, the differentiation between CCP and the corresponding (same colour) pure-line variety increases as well.

The dots belonging to CS (low seeding rate: $50 \mathrm{~kg} / \mathrm{ha}$ ) are clearly distinct in all three ways: they occupy the top positions in number of fertile tillers, show the highest level of dispersion and the clearest separation between the pure line variety (triangles) and CCP (circles) recordings. This corresponds with the higher number of significant differences in variation as shown by the univariate analysis. On the other extreme of the gradient, all the recordings at IN (high seeding rate: $210 \mathrm{~kg} / \mathrm{ha}$ ) and VD (extreme competition from perennial grasses) show a lower level of dispersion compared to CS and hardly any separation between the pure-line variety and CCP. This corresponds with the low number of significant differences in variation as shown by the univariate analysis.

Contributions of each variable to the construction of the axes are presented in Table 3 and Figure 3. Values in Table 3 are projections of the original variable vectors on the first three principal components.

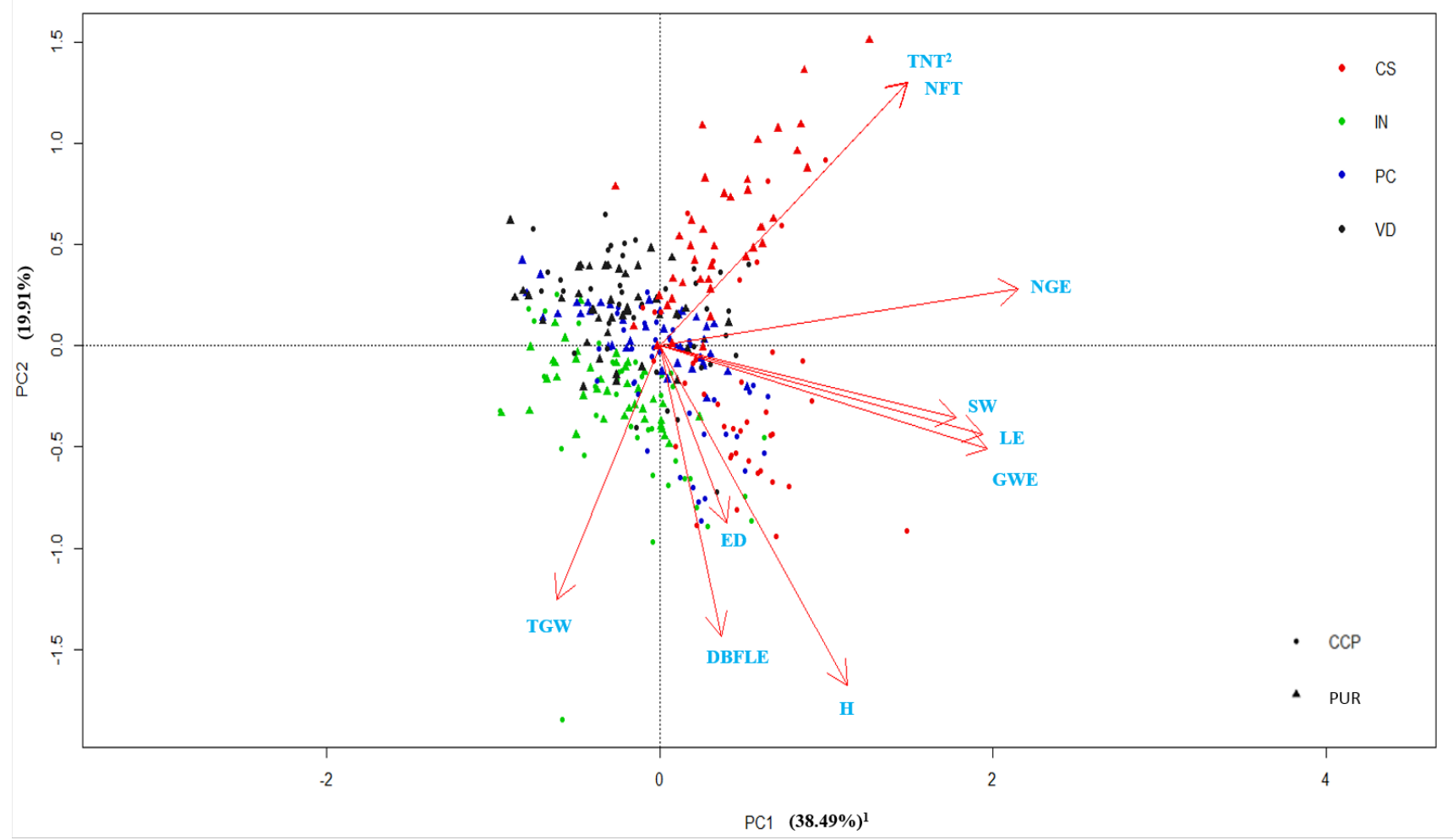

Figure 3. Graphic representation of the first two components of the Principal Components Analysis. The different colours distinguish the four different sites: VD, IN, PC and CS. CCP = Composite Cross Population, PUR = Pure line. ${ }^{1}$ The percentage indicates the contribution of the component to the explanation of the total variation within the dataset. ${ }^{2}$ Red arrows indicate measured parameters. Their abbreviations are detailed in Table 3. 
Table 3. Description of contributions of each variable to the three principal components PC1, PC2 and PC3.

\begin{tabular}{|c|c|c|c|c|c|}
\hline Abbreviation & Description & Units & $\mathrm{PC} 1$ & PC2 & PC3 \\
\hline NFT & Number of fertile tillers & number & 1.48 & 1.30 & 1.28 \\
\hline TNT & Total number of tillers & number & 1.49 & 1.30 & 1.25 \\
\hline H & Length of longest tiller & $\mathrm{cm}$ & 1.13 & -1.67 & 0.10 \\
\hline LE & Length of ear on longest tiller & $\mathrm{cm}$ & 1.94 & -0.44 & -0.72 \\
\hline DBFLE & Distance from the basis of flag leaf to ear basis on longest tiller & $\mathrm{cm}$ & 0.37 & -1.44 & 0.97 \\
\hline SW & Straw width at first node of longest tiller & $\mathrm{mm}$ & 1.78 & -0.36 & -0.71 \\
\hline NGE & Number of grains of ear of longest tiller & number & 2.15 & 0.28 & -0.50 \\
\hline GWE & Weight of grains of ear of longest tiller & $g$ & 1.96 & -0.50 & -0.09 \\
\hline TGW & Thousand Grain Weight (GWE over NGE x 1000) & $g$ & -0.62 & -1.26 & 1.12 \\
\hline ED & Ear density around plant & Number.m ${ }^{-2}$ & 0.40 & -0.88 & 0.90 \\
\hline
\end{tabular}

Ear density (ED), a key parameter of yield, contributes weakly to the first three principal components. By contrast, vegetative parameters particularly linked to tillering (TNT) and ear production (NFT) contribute to a large degree to all three principal components. Their variation dominates the data set and pilots the gradient of farms from the minima at $I N$, via PC and VD to the maxima at CS. The first principal component (PC1) expresses a positive co-variation for all parameters recorded on individuals, except TGW, which contributes negatively. The second principal component (PC2) represents a negative co-variation. This component reveals a subgroup within the dataset, in which individu- als were dwarfed but had strongly tillered in low seeding rate conditions. This subgroup belongs mostly to pure line recordings at $C S$ that were affected by the slug invasion. The last component (PC3) accounts for another subgroup that did not follow the mainstream variation of PC1, and is characterized by high ear density (ED), short ears (LE), low number of grains per ear (NGE), but an extremely high thousand grain weight (TGW). As the projection on the (PC1, PC3) - plane shows (Figure 4), this variation is driven by plants found at IN (see also Figure 1 that reveals the outliers in TGW from IN).

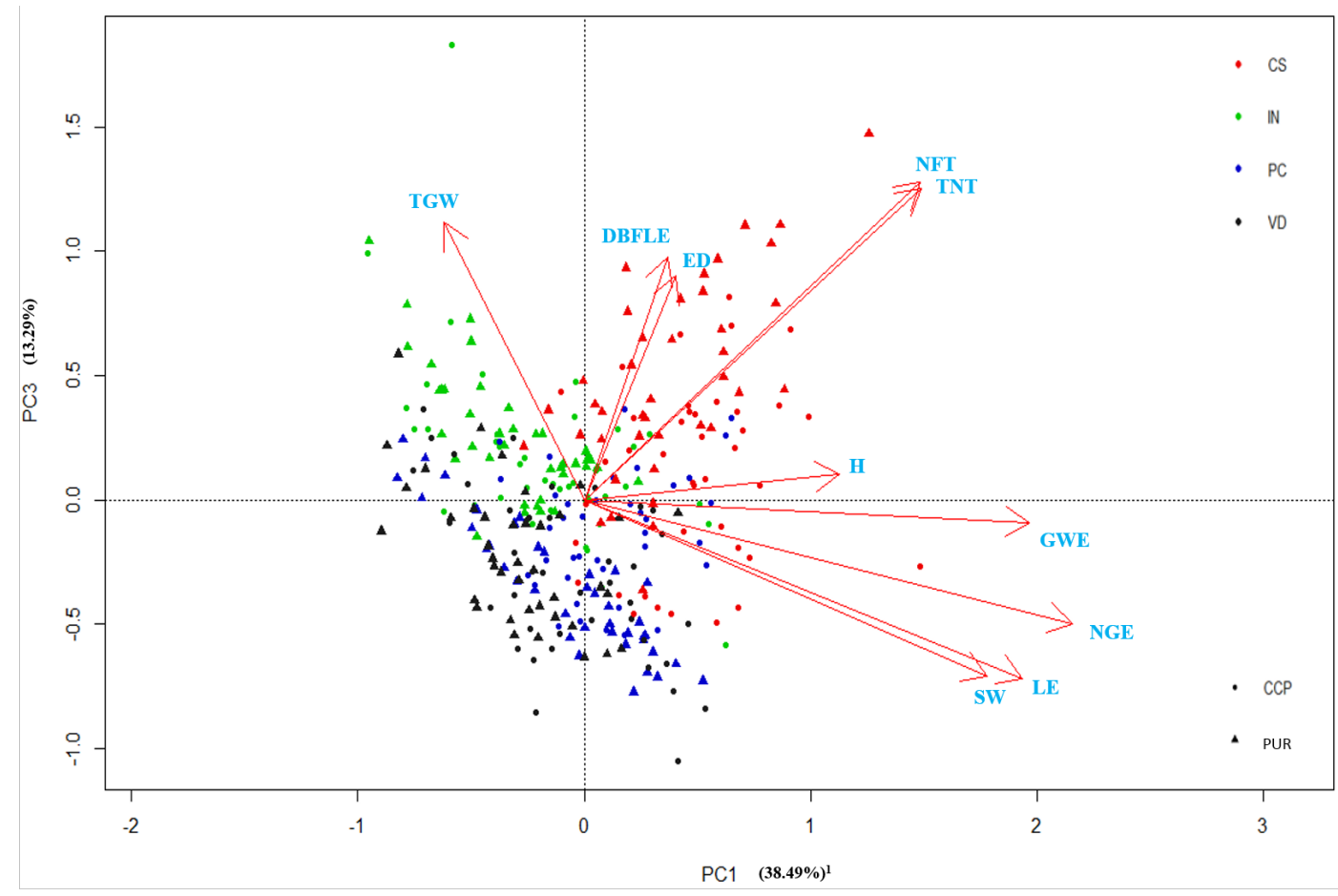

Figure 4. Graphic representation of the first and third components (PC1 and PC3) of the Principal Components Analysis. The different colours distinguish the four different sites: VD, IN, PC and CS. CCP = Composite Cross Population, PUR = Pure line. ${ }^{1}$ The percentage indicates the contribution of the component to the explanation of the total variation of data. Red arrows indicate measured parameters. Their abbreviations are detailed in Table 3. 


\section{Discussion}

Within an emerging bread wheat renewal movement connecting farmers, millers, bakers and households in Belgium, this study explored the combination of two intensely researched and debated innovations towards ecological intensification: genetic diversification through for example CCPs and the System of Wheat Intensification (SWI). We compared the phenotypic expression of one CCP grown in four different settings during the same cropping cycle (2015-2016). Seeding rate is one of the main differences, as it varied from 50 to $210 \mathrm{~kg} \mathrm{ha}^{-1}$. Before discussing the results it is important to stress that the four farms cropped this same CCP yet took their own, particular management decisions. For instance, they chose the pure line variety independently from one another and from the researchers involved. This has important implications for the way the data could and should be analysed and interpreted. We come back to this issue at the end of the discussion.

\subsection{Effect of Seeding Rate on Yield Components}

As this work was carried out in farmers' fields, it was not possible to harvest plots to estimate the final grain yield. Also, since we measured only the dominant ear per plant, our recordings do not reflect the overall behaviour of the crop. Yet our results reopen an old question on the "optimal" seeding rate. This question has been around for a long time, as evidenced by 18th and 19th century writings [3941]. It was only during agricultural modernization that the practice of growing high-density wheat became widespread, with increasing use of mineral fertilisers and plant protection products and the selection of pure lines [42]. Tillering, seed set and grain filling are compensatory mechanisms influencing final yield and influenced in turn by seeding rate and seedling density [43-48]. As a rule of thumb, TGW decreases when plant densities and/or seeding rates increase [43-48]. Moreover, in his classic study Darwinkel [43] shows that an increase of plant density (from 5 to 800 plants $\mathrm{m}^{-2}$ ) causes a decrease in the number of fertile spikelets per ear as soon as plant density is higher than 25 plants $\mathrm{m}^{-2}$. According to this author, the higher the plant density, the stronger the inter-individual competition and the decrease of carbohydrates supply through photosynthesis, necessary to feed the growth of fertilised spikelets. In this way, a decrease of seeding rate and/or final plant density could enhance grain yield per ear, as an old French saying expresses: "Qui sème menu récolte drû" (Who seeds economically harvests abundantly) and as an old book on "family cropping" of wheat describes in detail [49].

At first sight, our inter-site comparison of TGW runs counter this rule of thumb. In the site IN (highest seeding rate), we observed a mean TGW significantly superior to those of three other sites, whatever the variety. Two observations may explain this. First, in this site, there were three unusually high values relative to the rest of the dataset (Figure 1). Second, this high TGW can be explained by a stress period (in the case of IN: exceptionally high rainfall and nutrient leaching combined with high humidity and low radiation in June) during flowering and seed set. In wheat, the number of grains per ear is fixed through a period of 30 days around flowering. Studies have shown that a particularly severe plant stress in this period can lead to a decrease in the number of grains per ear $[50,51]$. If, because of a particular stress during that critical period, not much seed per ear was set, the tiller has excess photosynthetic capacity to fill a small number of grains, leading to exceptionally high TGW values. Viewed in this way, increased TGW can partially compensate for an extremely low seed set.

Despite the very different initial seeding rates, we found that the final ear density was remarkably steady among sites (with the exception of VD because of the intense competition with perennial grasses). For pure lines and among IN-PC-CS, ear density was in a "steady state" around 310 to 400 ears $\mathrm{m}^{-2}$ regardless of the initial seeding rate. This steady state was more pronounced for CCP, with values around 350 ears $\mathrm{m}^{-2}$ and insignificant inter-site differences. Furthermore, the values we recorded were comparable to the standard target ear density in organic farming, which is around 300 ears $\mathrm{m}^{-2}$.

This stability of ear density despite huge variations in seeding rate is the typical result of compensation between yield components through tillering in response to low seeding rates (and conversely, the impossibility of tillering at high seeding rates). This result questions high seeding rates especially in organic farming with a renewed interest in local adaptation and seed saving (made easier by the lower amount of seed that needs to be stored and sorted). Indeed, for seed saving purposes, the practice of sowing at low densities (down to $10-30 \mathrm{~kg} \mathrm{ha}^{-1}$ ) has many advantages in terms of mass selection (typically post-harvest, in SWI, on thousand grain weight) and seed saving. However, during the 1960 s and 1970s, standard wheat seeding rates have been set at 150-200 $\mathrm{kg} \mathrm{ha}^{-1}$, whether cropped chemically or not. This rate has been fixed with the idea that each established plant produces one or two fertile tillers to minimize intra-individual competition between the successive ears. In conventional farming, the main justification is that wheat is often sown rather late in the fall (after the potato, corn or sugarbeet harvest) and high seeding rates ensure a dense stand irrespective of what happens during fall and winter (presence of aphids, frost damage...). Organic farmers also usually stick to dense seeding to obtain dense stands quickly, as an insurance against excessive weed growth and bird predation (because seeds are not treated). In this respect, mixed cropping might be a pathway for new research to reconcile the risk of excessive weed growth with enhancing phenotypic expression when engaging into SWI.

\subsection{Effect of Seeding Rate on Phenotypic Differenciation: Potential for Selection}

Based on our observations of their effect on yield components, the standard seeding rates can already be ques- 
tioned. The observations on the potential for phenotypic expression reinforce this questioning.

For traits such as straw width and length, where the CCP is on average sturdier and taller than modern dwarf varieties, the difference was clearest at low seeding rates. More broadly speaking, the patterns revealed between the four sites suggest that both for the differentiation between varieties as for the differentiation of genotypes within population varieties, the sites with the lower seeding rates (PC and CS) gave the best phenotypic expression. This crucial aspect has not attracted much attention so far among researchers on participatory and evolutionary cereal breeding who plead for on-farm mass selection within population varieties regardless seeding rates. Paradoxically, a rule of thumb among plant breeders is to create genetic diversity first, and second to enhance the phenotypic expression of this genetic diversity in the field through the practice of spaced planting, to ease visual selection.

Conversely, to make the most of SWI, the more tillering capacity the better, and the CCP has shown stronger tillering when faced with strong competition with perennial grasses (VD) and a better phenotypic expression of its variation in tillering capacity under low seeding rates (CS). This trait is also looked for when selecting for weed competitiveness in organic farms. However, in standard selection protocols with high seeding rates under chemical protection, these traits are at best secondary to yield potential. Putatively, then, CCPs or any pre-Green Revolution varieties might be better adapted to the SWI than modern dwarf pure line varieties. Experimentation with various types of wheat populations (CCPs but also dynamic populations of landraces or CCPs created with landraces) should be continued.

\subsection{On-farm Experimentation: a Challenge for Participatory Research}

Because varieties were cropped differently in each site, it is not possible to conclude that seeding rate is the main factor influencing the expression of inter- and intra-varietal differentiation. Other factors, such as fertilisation intensity, microclimate and soil differences may have played a role as well. However, the data presented here at least question the interaction between the seeding rate and the phenotypic expression potential of a CCP. Indeed, the seeding rate varied widely among sites and one can safely assume that PC, IN and CS implement cropping systems aiming for a reasonably high yield and yield stability [52,53]. Our approach was exploratory, "light" (as non-interventionist as possible) and adaptive. It is a first step to answer some of the questions and concerns arising from farmers' networks we work with. In classical agronomical experimentation however, the modus operandi is factor-oriented with maximum noise control to study the influence of a limited number of particular factors on one or two variables supposing "et ceteris paribus". Because this was not our context, we opted for pattern analysis, to complement what limited variance analysis we could do. This pattern analysis gave the best overall perspective. Indeed, multivariate and especially nonparametric statistical analysis methods can successfully complement and even replace classical univariate methods and/or highly parametric variance analysis (mixed linear modelling as a generalization). However, pattern analysis asks for a more ecological modus operandi on data collection, analysis and especially interpretation when experimenting on-farm and comparing among farms. This approach is still different from the Bayesian alternative described by Rivière et al. [54], because for Bayesian analysis to work, data need to be collected on a large number of farms applying the same design, to compensate for the lack of replicates within each farm.

This work started as an informal collaboration between farmers and researchers to explore emerging questions among them. Because of time and material constraints, we limited this study to easy-access aboveground parameters that were measured during a one-shot operation (no phenological follow-up) and left aside belowground or laboratorybased parameters. However, continued experimentation is envisaged in three ways:

1. Throughout the four sites, the CCP stood out in several aspects. For example, differences in soil surface and biotic activity were observed between the CCP and the pure line variety. These may be related to systematic recorded sturdiness of the CCP plants (stronger and longer straw, pointing to possibly more extensive rooting) but these aspects need further investigation. Despite the taller stature of the CCP and the very adverse weather conditions during inter-node elongation (June), no lodging was observed. This warrants further investigations since the main reason why dwarf genes have been crossed into modern wheat varieties was to prevent the typical lodging because of excessive internode elongation in response to high soluble nitrogen fertilisation. It might be argued that taller varieties are less interesting for bread wheat purposes, because they produce more straw and less grain (lower harvest index). However, in Darwinkel's study of 1978, the harvest index drops with increasing plant densities, and that drop sharpens suddenly above 100 plants $\mathrm{m}^{-2}$. Sturdier varieties might thus actually need lower seed rates than the standard seeding rates for modern dwarf varieties.

2. As for SWI itself, farmers and researchers alike maintain that in a less dense crop, plants are less diseaseprone and less photosynthesis is wasted to non-fertile tillers, but these aspects need crop monitoring during tillering, flowering and seed set. Phenologically also, questions pop up on inter-individual communication mechanisms such as through mycorrhizal linkages and the way intra-plant competition between successive tillers influences seed set and ear filling under different seeding rates. Finally, the prospect of on-farm mass selection begs the question whether it is relevant to mass select on tillering capacity (pre-harvest) 
and/or thousand grain weight (post-harvest) or yet other parameters, and if farmers have the capacity to act on these criteria, given their time constraints and the highly multi-focused nature of their work. Indeed, SWI demands optimal growing conditions that may entail reconsidering a series of established farming practices (crop rotation and mixed cropping, field preparation, adapted machinery...) and might be labour intensive. To study the diversity of these interconnected questions in depth, a broadening network of farmers linking up with a broadening diversity of researchers is needed.

3. For decades after World War II, the issues of crop genetic diversity and plant husbandry have been translated in breeding and cropping recipes within an agronomic school of thought that did not question the use of harmful chemicals and strived for the development of fairly standard recipes. The recent and strong call for an ecologization of farming means however, that many of these recipes must be broken up again, and underlying issues analysed through an agroecological lens. This may take us in opposite directions. For example, Weiner et al. [55] suggest the idea of very high seed densities for increased sustainability of cereal cropping systems, mainly by reducing crop-weed competition and thus weed control measures. However, this type of approach does not take into account the wealth of interconnected questions which experimenting SWI $x$ CCP reopens. In addition to participatory decentralised experiments, a novel type of experimental farm is needed to centralise, organise, communicate and broker knowledge between farms, farmers, research and researchers. Through open-field days, communication among farmers and researchers on these highly interconnected aspects of wheat cropping should then be eased. However, current extension services rarely take up farmers' questions and cannot finance nor justify this type of activities. New forms of knowledge brokering are necessary for participatory research so that farmers' questions are tackled and analysed within a socially and locally embedded novel research arena.

\section{References and Notes}

[1] Delcour A, Stappen FV, Gheysens S, Decruyenaere V, Stilmant D, Burny $P$, et al. Etat des lieux des flux céréaliers en Wallonie selon différentes filières d'utilisation. Biotechnologie, Agronomie, Société et Environnement. 2014;18:181-192.

[2] Baltazar $S$, Visser $M$, Dendoncker N. Au-delà des idées reçues. Études rurales. 2018;(202):18-35. doi:10.4000/etudesrurales. 14553.

[3] Bonnin I, Bonneuil C, Goffaux R, Montalent P, Goldringer I. Explaining the Decrease in the Genetic Diversity of Wheat in France over the 20th Century. vol. 195; 2014. doi:10.1016/j.agee.2014.06.003.

[4] Zhu YG, Smith SE, Barritt AR, Smith FA. Phosphorus (P) Efficiencies and Mycorrhizal Responsiveness of Old and Modern Wheat Cultivars; 2001.

\section{Conclusions}

This study confirms that genetically diverse varieties of winter wheat, such as CCPs, produce heterogeneous crops capable of adapting to diverse environments and hence to annual variations in weather / rainfall patterns associated with climate change. The four environments in this study are especially differentiated by seeding rate, with SWI on the one side and a common high seeding rate on the other. Our results show that the high seeding rate does not allow the full expression of the genetic diversity embodied by a CCP, whereas lower seed rates allow more expression. This expression potential should be explored, particularly in the case of participatory plant breeding and seed saving on farm. The visual selection process could be enhanced by reducing seeding rates and applying other interrelated practices specific to SWI. Thus SWI offers an efficient agronomical perspective to be connected to on-farm breeding and to other agronomical innovations. Our results are of particular interest for organic farming which calls for a holistic vision of farming systems.

Several highly entwined questions raised during this experiment still need to be tackled and further participatory experimentation is already in progress. Apart from lack of institutional support, one major drawback of experimenting on-farm and within farm networks on questions like population varieties and SWI is that farmers and researchers alike need to adopt new postures to overcome the manifold barriers to collaboration.

\section{Acknowledgments}

We first like to thank the farmers involved in this work, and their numbers exceed the ones involved in this particular paper. Their views, not just on population varieties and SWI, but more globally on how to foster new ways of practicing research have greatly influenced us. Thanks also to the reviewers for careful reading and constructive comments to improve the first draft.
[5] Fan MS, Zhao FJ, Fairweather-Tait SJ, Poulton PR, Dunham SJ, McGrath SP. Evidence of Decreasing Mineral Density in Wheat Grain over the Last 160 Years. Journal of Trace Elements in Medicine and Biology. 2008;22(4):315-324. doi:10.1016/j.jtemb.2008.07.002.

[6] Chateil C, Goldringer I, Tarallo L, Kerbiriou C, Le Viol I, Ponge JF, et al. Crop Genetic Diversity Benefits Farmland Biodiversity in Cultivated Fields. Agriculture, Ecosystems \& Environment. 2013;171:25-32. doi:10.1016/j.agee.2013.03.004.

[7] Hajjar R, Jarvis DI, Gemmill-Herren B. The Utility of Crop Genetic Diversity in Maintaining Ecosystem Services. Agriculture, Ecosystems \& Environment. 2008;123(4):261-270. doi:10.1016/j.agee.2007.08.003.

[8] Suneson CA. An Evolutionary Plant Breeding Method. Agronomy Journal. 1956;48(4):188-191. doi:10.2134/agronj1956.00021962004800040012x. 
[9] Döring TF, Knapp S, Kovacs G, Murphy K, Wolfe MS. Evolutionary Plant Breeding in Cereals-Into a New Era. Sustainability. 2011;3(12):1944-1971. doi:10.3390/su3101944.

[10] Dawson JC, Goldringer I. Breeding for Genetically Diverse Populations: Variety Mixtures and Evolutionary Populations. In: Organic Crop Breeding. Wiley-Blackwell; 2011. pp. 7798. Available from: https://onlinelibrary.wiley.com/doi/abs/10.1002/ 9781119945932.ch5. doi:10.1002/9781119945932.ch5.

[11] Wolfe MS, Baresel JP, Desclaux D, Goldringer I, Hoad S, Kovacs G, et al. Developments in Breeding Cereals for Organic Agriculture. Euphytica. 2008;163(3):323-346. doi:10.1007/s10681-008-9690-9.

[12] Ceccarelli S. Plant Breeding with Farmers. A technical manual. ICARDA, Aleppo, Syria; 2012. Available from: http: //www.researchgate.net/publication/236962212_Plant_Breeding with_Farmers__a_Technical_Manual_ICARDA_Aleppo_Syria/file/ 5046351a757e2c9025.pdf.

[13] Ceccarelli S, Grando S. Decentralized-participatory Plant Breeding: An Example of Demand Driven Research. Euphytica. 2007;155(3):349-360. doi:10.1007/s10681-006-9336-8.

[14] Pimbert MP. Participatory Research and On-farm Management of Agricultural Biodiversity in Europe. IIED; 2011.

[15] Chiffoleau Y, Desclaux D. Participatory Plant Breeding: The Best Way to Breed for Sustainable Agriculture? International journal of agricultural sustainability. 2006;4(2):119-130. doi:10.1080/14735903.2006.9684795.

[16] Cuéllar-Padilla M, Calle-Collado A. Can We Find Solutions with People? Participatory Action Research with Small Organic Producers in Andalusia. Journal of Rural Studies. 2011;27(4):372-383. doi:10.1016/j.jrurstud.2011.08.004.

[17] Osman AM, Chable V. Inventory of Initiatives on Seeds of Landraces in Europe. Journal of Agriculture and Environment for International Development. 2009;103(1/2):95-130.

[18] Pautasso M, Aistara G, Barnaud A, Caillon S, Clouvel P, Coomes OT, et al. Seed Exchange Networks for Agrobiodiversity Conservation. A Review. Agronomy for Sustainable Development. 2012;33(1):151175. doi:10.1007/s13593-012-0089-6.

[19] Rivière P. Méthodologie de la sélection décentralisée et participative: un exemple sur le blé tendre; 2014. Available from: https: //tel.archives-ouvertes.fr/tel-00959369/document.

[20] Thomas M, Demeulenaere E, Dawson JC, Khan AR, Galic N, Jouanne-Pin S, et al. On-farm Dynamic Management of Genetic Diversity: The Impact of Seed Diffusions and Seed Saving Practices on a Population-variety of Bread Wheat: On-farm Crop Metapopulation of Bread Wheat. Evolutionary Applications. 2012;5(8):779-795. doi:10.1111/j.1752-4571.2012.00257.x.

[21] Dawson J, Rivière P, Berthellot JF, Mercier F, DE KOCHKO P, Galic $\mathrm{N}$, et al. Collaborative Plant Breeding for Organic Agricultural Systems in Developed Countries. Sustainability. 2011;3:1206-1223. doi:doi:10.3390/su3081206.

[22] Chable V, Dawson J, Bocci R, Goldringer I. Seeds for Organic Agriculture: Development of Participatory Plant Breeding and Farmers' Networks in France. Springer, Dordrecht; 2014. doi:10.1007/978-94007-7927-3_21.

[23] Almekinders CJM, Mertens L, Loon JP, Bueren ETL. Potato Breeding in the Netherlands: A Successful Participatory Model with Collaboration between Farmers and Commercial Breeders. Food Security. 2014;6(4):515-524. doi:10.1007/s12571-014-0369-x.

[24] Stoop WA, Uphoff N, Kassam A. A Review of Agricultural Research Issues Raised by the System of Rice Intensification (SRI) from Madagascar: Opportunities for Improving Farming Systems for Resource-poor Farmers. Agricultural Systems. 2002;71(3):249-274. doi:10.1016/S0308-521X(01)00070-1.

[25] Abraham B, Araya H, Berhe T, Edwards S, Gujja B, Khadka RB, et al. The System of Crop Intensification: Reports from the Field on Improving Agricultural Production, Food Security, and Resilience to Climate Change for Multiple Crops. Agriculture \& Food Security. 2014;3:4. doi:10.1186/2048-7010-3-4.

[26] Adhikari P, Araya H, Aruna G, Balamatti A, Banerjee S, Baskaran $P$, et al. System of Crop Intensification for more Productive, Resource-conserving, Climate-resilient, and Sustainable Agriculture: Experience with Diverse Crops in Varying Agroecologies. International Journal of Agricultural Sustainability. 2018;16(1):1-28. doi:10.1080/14735903.2017.1402504.

[27] Stoop WA. The Scientific Case for System of Rice Intensification and its Relevance for Sustainable Crop Intensification. International Journal of Agricultural Sustainability. 2011;9(3):443-455. doi:10.1080/14735903.2011.583483.

[28] Stoop WA, Sabarmatee, Sivasubramanian P, Ravindra A, Sen D, Prasad S, et al. Opportunities for Ecological Intensification: Lessons and Insights from the System of Rice/Crop Intensification - their Implications for Agricultural Research and Development Approaches. CAB Reviews. 2017;12(36):1-19.

[29] Ninou EG, Mylonas IG, Tsivelikas A, Ralli P, Dordas C, Tokatlidis IS. Wheat Landraces Are Better Qualified as Potential Gene Pools at Ultraspaced rather than Densely Grown Conditions. The Scientific World Journal. 2014;2014. Available from: https://www.ncbi.nlm.nih. gov/pmc/articles/PMC4037628/. doi:10.1155/2014/957472.

[30] Uphoff N, Fasoula V, Iswandi A, Kassam A, Thakur AK. Improving the Phenotypic Expression of Rice Genotypes: Rethinking "Intensification" for Production Systems and Selection Practices for Rice Breeding. The Crop Journal. 2015;3(3):174-189. doi:10.1016/j.cj.2015.04.001.

[31] Wolfe MS, Hinchsliffe KE, Clarke SM, Jones H, Haigh Z. Evolutionary Breeding of Healthy Wheat: from Plot to Farm. Aspects of Applied Biology 79, What will organic farming deliver? COR 2006. 2006;pp. 47-50.

[32] Döring TF, Wolfe M, Jones H, Pearce H, Zhan J. Breeding for Resilience in Wheat-Nature's Choice; 2010.

[33] Döring TF, Annicchiarico P, Clarke S, Haigh Z, Jones HE, Pearce $\mathrm{H}$, et al. Comparative Analysis of Performance and Stability among Composite cross Populations, Variety Mixtures and Pure Lines of Winter Wheat in Organic and Conventional Cropping Systems. Field Crops Research. 2015;183:235-245. doi:10.1016/j.fcr.2015.08.009.

[34] Bertholdsson NO, Weedon O, Brumlop S, Finckh MR. Evolutionary Changes of Weed Competitive Traits in Winter Wheat Composite cross Populations in Organic and Conventional Farming Systems. European Journal of Agronomy. 2016;79:23-30. doi:10.1016/j.eja.2016.05.004.

[35] De Mendiburu F. Agricolae: Statistical Procedures for Agricultural Research. R package version, R CRAN; 2014.

[36] Maechler M. Cluster: Cluster Analysis Extended Rousseeuw et al. R package version, R CRAN; 2013.

[37] Oksanen J, Blanchet F, Friendly M, Kindt R, Legendre P, McGlinn D, et al. Vegan: Community Ecology Package. $R$ package version, $R$ CRAN; 2016.

[38] Donald CM. The breeding of crop ideotypes. Euphytica. 1968;17(3):385-403. doi:10.1007/bf00056241.

[39] Hallett FF. On Pedigree in Wheat as a Means of Increasing the Crop. Journal of The Royal Agricultural Society of England. 1861;22(48):371-381.

[40] Vilmorin-Andrieux. Les Meilleurs blés, description et culture des principales variétés de froments d'hiver et de printemps. Vilmorinandrieux \& cie ed.; 1880. Available from: https://gallica.bnf.fr/ark: /12148/bpt6k96777743.

[41] Mémoires d'agriculture, d'économie rurale et Domestique. Paris, France: Société Royale d'agriculture de Paris; 1785.

[42] Bonneuil C, Thomas F. Gènes, pouvoirs et profits. Recherche publique et régimes de production des savoirs de Mendel aux OGM Quae; 2009. Available from: http://www.editions.ird.fr/produit/109/ 9782759201617/Genes\%20pouvoirs\%20et\%20profits.

[43] Darwinkel A. Patterns of tillering and grain production of winter wheat at a wide range of plant densities. Netherlands Journal of Agricultural Science. 1978;26:383-398.

[44] Bodson B. Rôle de la densité des semis, de la largeur des interlignes de semis et de la fumure azotée dans l'intensification de la culture du froment d'hiver. Leurs effets sur le rendement et sur les composantes du rendement; 1986. Available from: https://orbi.uliege.be/handle/2268/40088.

[45] Darwinkel A, Hag B A T, Kuizenga J. Effect of Sowing Date and Seed Rate on Crop Development and Grain Production of Winter Wheat. Netherlands Journal of Agricultural Science. 1977;25:83-94.

[46] Spink JH, Semere T, Sparkes DL, Whaley JM, Foulkes MJ, Clare RW, et al. Effect of Sowing Date on the Optimum Plant Density of Winter Wheat. Annals of Applied Biology. 2005;137(2):179-188. 
doi:10.1111/j.1744-7348.2000.tb00049.x

[47] Valério IP, Carvalho FIF, Benin G, Silveira G, Silva JAG, Nornberg $\mathrm{R}$, et al. Seeding Density in Wheat: The more, the Merrier? Scientia Agricola. 2013;70(3):176-184. doi:10.1590/S010390162013000300006

[48] Gooding MJ, Pinyosinwat A, Ellis RH. Responses of Wheat Grain Yield and Quality to Seed Rate. The Journal of Agricultural Science. 2002;138(3):317-331. doi:10.1017/S0021859602002137.

[49] Sauvageot P, Grillo P. La culture familiale du blé. Facteur de renaissance française. Paris: Sequana; 1943.

[50] Fischer RA. Number of Kernels in Wheat Crops and the Influence of Solar Radiation and Temperature. The Journal of Agricultural Science. 1985;105(2):447-461. doi:10.1017/S0021859600056495.

[51] Demotes-Mainard S, Jeuffroy MH. Effects of Nitrogen and Radiation on Dry Matter and Nitrogen Accumulation in the Spike of Winter Wheat. Field Crops Research. 2004;87(2):221-233. doi:10.1016/j.fcr.2003.11.014
[52] Dewaele K, Temmerman F, Delanote L. Performance of Winter Wheat CCP's in Comparison to Reference Varieties in Organic Field Trials in Belgium; 2015. Available from: http://orgprints.org/29864/.

[53] FAO. Agroecology for Food Security and Nutrition Proceedings of the FAO International Symposium. 18-19 September 2014, Rome Italy: Biodiversity \& Ecosystem Services in Agricultural Production Systems. FAO; 2015. Available from: www.fao.org/3/a-i4729e.pdf.

[54] Rivière P, Dawson JC, Goldringer I, David O. Hierarchical Bayesian Modeling for Flexible Experiments in Decentralized Participatory Plant Breeding. Crop Science. 2015;55(3):1053. doi:10.2135/cropsci2014.07.0497.

[55] Weiner J, Andersen SB, Wille WKM, Griepentrog HW, Olsen JM. Evolutionary Agroecology: The Potential for Cooperative, High Density, Weed-suppressing Cereals. Evolutionary Applications. 2010;3(5 6):473-479. Available from: https://www.ncbi.nlm.nih.gov/pmc/ articles/PMC3352502/. doi:10.1111/j.1752-4571.2010.00144.x. 